3. Lavrov DV, Brown WM, Boore JL. Phylogenetic position of the Pentastomida and (pan)crustacean relationships. Proc Biol Sci. 2004;271:537-44. http://dx.doi.org/10.1098/rspb.2003.2631

4. Yao MH, Wu F, Tang LF. Human pentastomiasis in China: case report and literature review. J Parasitol. 2008;94:1295-8. http://dx.doi.org/10.1645/GE-1597.1

5. Latif B, Omar E, Heo CC, Othman N, Tappe D. Human pentastomiasis caused by Armillifer moniliformis in Malaysian Borneo. Am J Trop Med Hyg. 2011;85:878-81. http://dx.doi.org/ 10.4269/ajtmh.2011.11-0404

6. Tappe D, Meyer M, Oesterlein A, Jaye A, Frosch M, Schoen C, et al. Transmission of Armillifer armillatus ova at snake farm, The Gambia, West Africa. Emerg Infect Dis. 2011;17:251-4. http://dx.doi.org/10.3201/eid1702.101118

7. Meyers WM, Neafie RC, Connor DH. Pentastomiasis. In: Binford $\mathrm{CH}$, Connor DH, editors. Pathology of tropical and extraordinary diseases. Washington (DC): Armed Forces Institute of Pathology; 1976. p. $546-50$.

8. Dakubo JCB, Etwire VK. Human pentastomiasis in upper east region of Ghana: report of two cases. Postgrad Med J Ghana. 2014;3:56-60.

9. Mouchet R. Note sur Porocephalus moniliformis. Bull Soc Path exot. 1914;7:497-501.

10. Prathap K, Lau KS, Bolton JM. Pentastomiasis: a common finding at autopsy among Malaysian aborigines. Am J Trop Med Hyg. 1969;18:20-7. http://dx.doi.org/10.4269/ajtmh.1969.18.20

Address for correspondence: Idzi Potters, Department of Clinical

Sciences, Institute of Tropical Medicine Antwerp, Kronenburgstraat 43/3, 2000 Antwerp, Belgium; email: ipotters@itg.be

\section{Influenza A(H9N2) Virus, Burkina Faso}

\section{Bianca Zecchin, ${ }^{1}$ Germaine Minoungou, ${ }^{1}$ Alice Fusaro, Sidi Moctar, Anne Ouedraogo-Kaboré, Alessia Schivo, Annalisa Salviato, Sabrina Marciano, Isabella Monne}

Author affiliations: Istituto Zooprofilattico Sperimentale delle Venezie, Legnaro, Padova, Italy (B. Zecchin, A. Fusaro, A. Schivo, A. Salviato, S. Marciano, I. Monne); Laboratoire National d'Elevage de Ouagadougou, Ouagadougou, Burkina Faso (G. Minoungou, S. Moctar, A. Ouedraogo-Kaboré)

DOI: https://doi.org/10.3201/eid2312.171294

We identified influenza $A(H 9 N 2)$ virus $\mathrm{G} 1$ lineage in poultry in Burkina Faso. Urgent actions are needed to raise awareness about the risk associated with spread of this zoonotic virus

${ }^{1}$ These authors contributed equally to this article. subtype in the area and to construct a strategy for effective prevention and control of influenza caused by this virus.

Since their detection in China in 1992, influenza $\mathrm{A}_{\text {A(H9N2) viruses have caused large economic losses to }}$ the poultry industry and have occasionally been transmitted to mammalian species, including humans. Three main genetic lineages were described among the Eurasian H9N2 subtype viruses: G1, Y280, and Y439 (Korean) lineage (1). In the past decade, the G1 lineage has spread mostly in gallinaceous birds across Asia, the Middle East, and eventually North Africa, where H9N2 outbreaks were reported in Libya (2006 and 2013) (2), Tunisia (2010-2012) (3), Egypt (2011-present), and Morocco (2016) (4).

The Veterinary Services of Ouagadougou, Burkina Faso, submitted 30 tracheal swab specimens and 10 organ samples collected in January 2017 in Burkina Faso to the World Organisation for Animal Health/Food and Agriculture Organization of the United Nations Reference Laboratory for Avian Influenza, Istituto Zooprofilattico Sperimentale delle Venezie (Legnaro, Padova, Italy). All samples were collected from a layer farm that was experiencing decreased egg production and respiratory signs among its flock; the animals were suspected to have infectious bronchitis virus (IBV).

Molecular analyses of the animal samples showed negative results for IBV and indicated that animals from the farm were infected with avian influenza $A(H 9 N 2)$ virus. The 8 gene segments were obtained for 1 representative virus by using a MiSeq Platform (Illumina, San Diego, CA, USA). Sequences were submitted to GenBank under accession numbers MF510849-56.

The maximum-likelihood phylogenetic tree of the hemagglutinin (HA) gene showed that the H9N2 subtype virus from Burkina Faso belonged to the G1 lineage, which has remarkable zoonotic potential. This virus clustered with H9N2 subtype viruses isolated in Morocco in 2016 (99.2\% similarity) and with an H9N2 subtype virus identified in the United Arab Emirates in 2015 (A/chicken/ Dubai/D2506.A/2015) (98.7\% similarity) (online Technical Appendix Figure 1, https://wwwnc.cdc.gov/EID/ article/23/12/17-1294-Teachapp1.pdf). Phylogenetic trees obtained for all other gene segments confirmed clustering with viruses from Morocco and the United Arab Emirates, similar to that observed for HA gene phylogeny.

Phylogeographic analysis (online Technical Appendix) identified multiple introductions of influenza A(H9N2) virus into North Africa from the Middle East and Pakistan. The H9N2 subtype virus identified in Burkina Faso seems to have originated from Morocco, although we cannot rule out the possibility that H9N2 subtype viruses were circulating in unsampled locations (online Technical Appendix Figure 2, Video, https://wwwnc.cdc.gov/EID/article/23/12/171294-V1.htm). 
Analyses of the deep sequencing data showed that $\approx 50 \%$ of the virus population in the tracheal swab specimen had leucine at position 226 (H3 numbering) of the HA receptor binding site (sequence coverage of 14,152 reads in the indicated position), which enables preferential binding to human-like $\alpha 2-6$-linked sialic acid receptors (5). Furthermore, a potential additional glycosylation site (NLS), which had not previously been detected in the G1 lineage, was identified at positions 271-273 (H3 numbering). In the acidic polymerase protein, the H9N2 subtype virus from Burkina Faso had the mutation PA-S409N, which is considered a host specificity marker of human influenza virus (6). The same mutation was detected in related viruses from Morocco and Dubai.

Identification of H9N2 subtype virus in West Africa, where highly pathogenic H5 strains of the A/goose/Guangdong/1/1996 lineage (Gs/GD) have been widely circulating since the beginning of 2015, is a concern because of animal health implications, negative effects on local economies, and possible emergence of reassortant viruses with unknown biological properties. Reassortment events between H9N2 and highly pathogenic H5N1 subtype viruses were reported in China in 2005 and $2016(7,8)$ and in Bangladesh in 2012 (9). In December 2013, an H5N1 subtype virus that had an H9N2 subtype polymerase basic 2 gene was reported in a patient in Canada who had returned from China (10). Moreover, H5N6 subtype reassortant viruses belonging to clade 2.3.4.4, which contain H9N2 subtype-like internal genes, were identified in China in 2015-2016 (8).

H5 strains belonging to clades 2.3.2.1c and 2.3.4.4 are currently circulating in West Africa. This finding, combined with detection of human-like receptor specificity and 2 mutations typical of human influenza viruses in the H9N2 subtype virus from Burkina Faso, might indicate emergence of a strain capable of infecting humans and warrants additional attention to the avian influenza situation in West Africa. Furthermore, identification of H9N2 subtype viruses in Morocco and Burkina Faso in chickens suggests that commercial poultry trade between North and West Africa might have played a key role in spread of the virus.

Involvement of wild birds in long-distance spread of H9N2 subtype G1 virus seems unlikely because this lineage is strongly adapted to poultry. These observations highlight the difficulty in tracing and containing circulating H9N2 subtype G1 virus and underline the need to review current approaches of disease reporting to understand spread and effects of this virus, which are probably underestimated. Thus, it is imperative to provide strategic guidance to countries in West Africa on technical and policy options for cost-effective surveillance and prevention and control of multiple cocirculating influenza virus strains.

\section{Acknowledgments}

We thank Silvia Ormelli and Francesca Ellero for providing excellent technical assistance and authors and originating and submitting laboratories for providing virus sequences from the GISAID EpiFlu Database (https://platform.gisaid.org; online Technical Appendix Table 2).

Dr. Zecchin is a biotechnologist at the Istituto Zooprofilattico Sperimentale delle Venezie, Padova, Italy. Her primary research interests include studying the molecular phylogeny and the evolutionary dynamics of viruses.

\section{References}

1. Peiris JS, Guan Y, Markwell D, Ghose P, Webster RG, Shortridge KF. Cocirculation of avian H9N2 and contemporary "human" H3N2 influenza A viruses in pigs in southeastern China: potential for genetic reassortment? J Virol. 2001;75:9679-86. http://dx.doi.org/10.1128/JVI.75.20.9679-9686.2001

2. Kammon A, Heidari A, Dayhum A, Eldaghayes I, Sharif M, Monne I, et al. Characterization of avian influenza and Newcastle disease viruses from poultry in Libya. Avian Dis. 2015;59:422-30. http://dx.doi.org/10.1637/11068-032215-ResNote.1

3. Tombari W, Ghram A. Production of a truncated recombinant HA1 for influenza A H9 subtype screening. Biologicals. 2016;44:54655. http://dx.doi.org/10.1016/j.biologicals.2016.07.006

4. El Houadfi M, Fellahi S, Nassik S, Guérin JL, Ducatez MF. First outbreaks and phylogenetic analyses of avian influenza H9N2 viruses isolated from poultry flocks in Morocco. Virol J. 2016;13:140. http://dx.doi.org/10.1186/s12985-016-0596-1

5. Wan H, Perez DR. Amino acid 226 in the hemagglutinin of H9N2 influenza viruses determines cell tropism and replication in human airway epithelial cells. J Virol. 2007;81:5181-91. http://dx.doi.org/10.1128/JVI.02827-06

6. Chen GW, Chang SC, Mok CK, Lo YL, Kung YN, Huang JH, et al. Genomic signatures of human versus avian influenza A viruses. Emerg Infect Dis. 2006;12:1353-60. http://dx.doi.org/ 10.3201/eid1209.060276

7. Dong G, Xu C, Wang C, Wu B, Luo J, Zhang H, et al. Reassortant H9N2 influenza viruses containing H5N1-like PB1 genes isolated from black-billed magpies in southern China. PLoS One. 2011; 6:e25808. http://dx.doi.org/10.1371/ journal.pone. 0025808

8. Chen LJ, Lin XD, Tian JH, Liao Y, Ying XH, Shao JW, et al. Diversity, evolution and population dynamics of avian influenza viruses circulating in the live poultry markets in China. Virology. 2017;505:33-41. http://dx.doi.org/10.1016/j.virol.2017.02.009

9. Monne I, Yamage M, Dauphin G, Claes F, Ahmed G, Giasuddin M, et al. Reassortant avian influenza A(H5N1) viruses with H9N2-PB1 gene in poultry, Bangladesh. Emerg Infect Dis. 2013;19:1630-4. http://dx.doi.org/10.3201/eid1910.130534

10. Pabbaraju K, Tellier R, Wong S, Li Y, Bastien N, Tang JW, et al. Full-genome analysis of avian influenza $\mathrm{A}(\mathrm{H} 5 \mathrm{~N} 1)$ virus from a human, North America, 2013. Emerg Infect Dis. 2014;20:887-91. http://dx.doi.org/10.3201/eid2005.140164

Address for correspondence: Bianca Zecchin, Istituto Zooprofilattico Sperimentale delle Venezie, Division of Comparative Biomedical Sciences, Viale dell’Università 10, 35020 Legnaro, Padova, Italy; email: bzecchin@izsvenezie.it 